\title{
Role of an Indigenous Drug (Achyranthes Aspera) in the Management of Reactions in Leprosy Preliminary Observations
}

\author{
I) IVAKAR OJHA, S. N. TRIPATHI** \\ GURMOHAN SINGH*** \\ (From the Department of Kayachikitsa, Post Graduate Institute of Indian Medicine, College of Medical Sciences, \\ Banaras Hindu University, Varanasi-5, India).
}

\section{IN TRODUCTION}

The treatment of reactions in leprosy has been largely empirical. Antimonials like potassium antimony tartrate (PAT), Fantorin and Stibatin have been mainly used for the past several decades. The antimalarials have come into use in recent years. In addition to these, there is yet another most potent group of drugs namely the corticosteroids $\left({ }^{2}\right)$.

Although, the drug of choice for these episodes are antimony preparations, especially 'PAT' because of its cheapness and therapeutic efficacy, but its use is restricted in rural conditions due to difficulty in its mode of administration, as it has to be administered intravenously and intromuscularly. Under these conditions antimalarials that could be administered orally come next in preference. But they are also not very safe considering their toxic manifestations in general. Corticosteroids are to be used in cases of severe or persistent reaction, agonising neuritis, or potentially serious eye complications. A serious drawback of corticosteroids is the rebound phenomenon when this therapy is discontinued. Therefore, further research is not unwanted.

Tripathi et al (1963), ( $\left.{ }^{3}\right)$, have observed that an indigenous drug 'Achyranthes aspera' of Natural order Amarantaceae, seems to be effective, in reaction and quiescent stage of the disease. In order to obtain additional data on this indigenous drug, the present study was undertaken.

MATERIAL AND METHODS

A group of 12 cases of reaction selected from the leprosy clinic of the out patient department of S. S. Hospital, B.H.U., formed the material for study of the therapeutic aspects of the reactive state and were studied in detail from the clinical, bacteriological and immunological points of view before starting the actual drug therapy. Criteria of diagnosis, of types, stages and grades of reactions in leprosy are given in Figs. I, 2 and 3 respectively.

All these cases were taking regular treatment from our out-door Leprosy-clinic which they were visiting twice a week. During the trial the dose of anti-leprosy drug DDS was either reduced or completely withdrawn, depending upon the severity of reaction. For the treatment of reaction a decoction of whole plant of Achyranthes aspera (Fig. 4), prepared by the methods described in classics of Ayurveda, was given orally. The dose of the decoction was I oz. twice daily. The patients in the stage of acute reaction were advised to take rest in bed. Intercurrent pathological conditions were attended duly. They were advised to take nutritious diet within their means and to observe the hygenic conditions as far as possible.

The ordinary treatment of leprosy patients was on a dosage of $10 \mathrm{mgm}$. of DDS daily which is increased by ro mgm. every week to a maximum of roo mgm. daily for 6 days a week. During the reactions the DDS dosage was either reduced or completely withdrawn as needed. For the treatment of reaction decoction of Achyranthes aspera was given orally at a dosage of I oz. decoction twice daily. The bacterial index was calculated in each case by taking smears from 8 sites.

*Lecturer in Kayachikitsa (Internal Medicine).

** Reader in Kayachikitsa (Internal Medicine).

*** Reader in Dermatology and Venereology. 


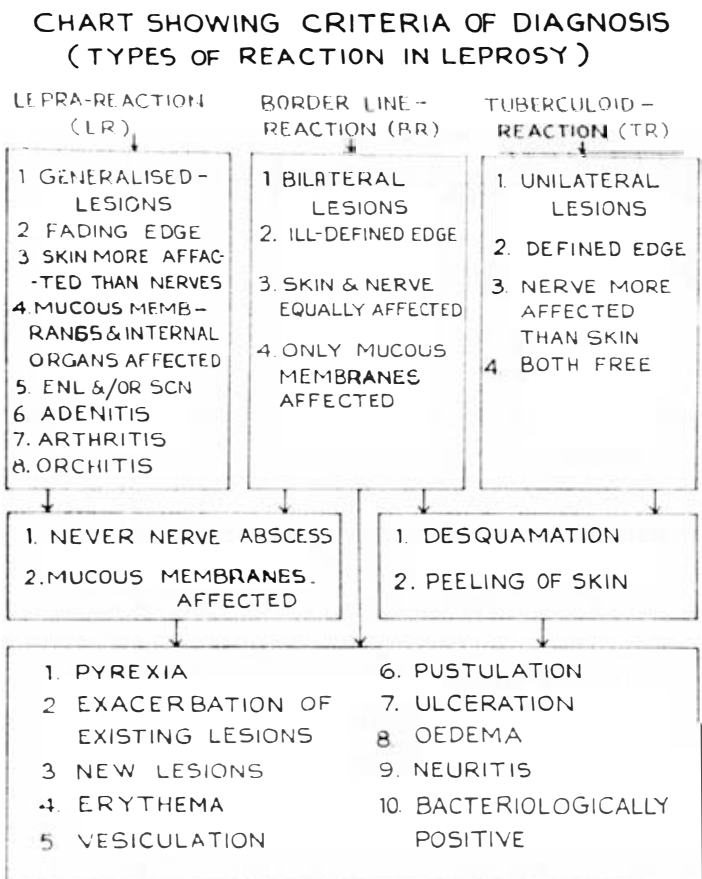

FIG. I

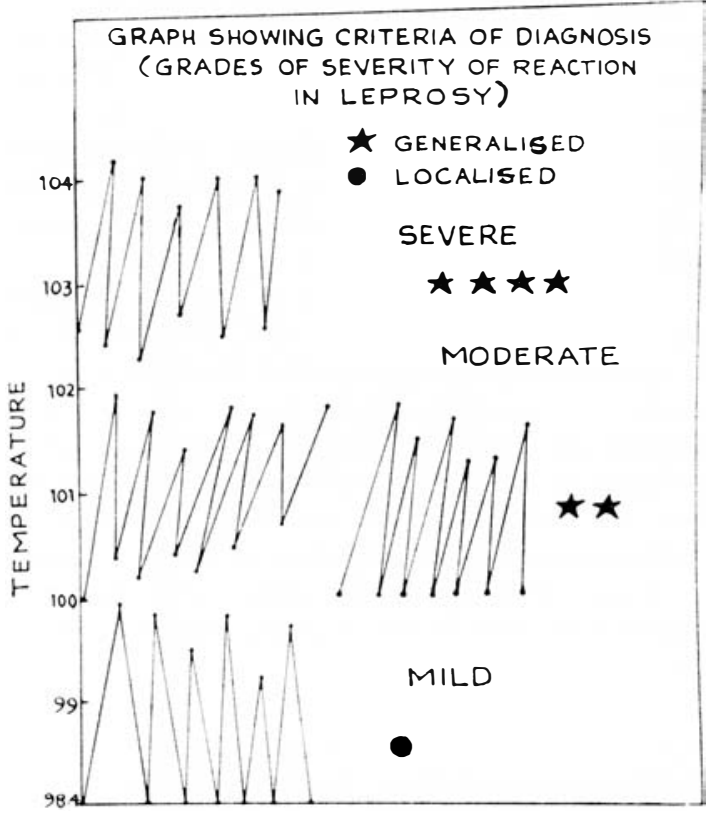

FIG. 3

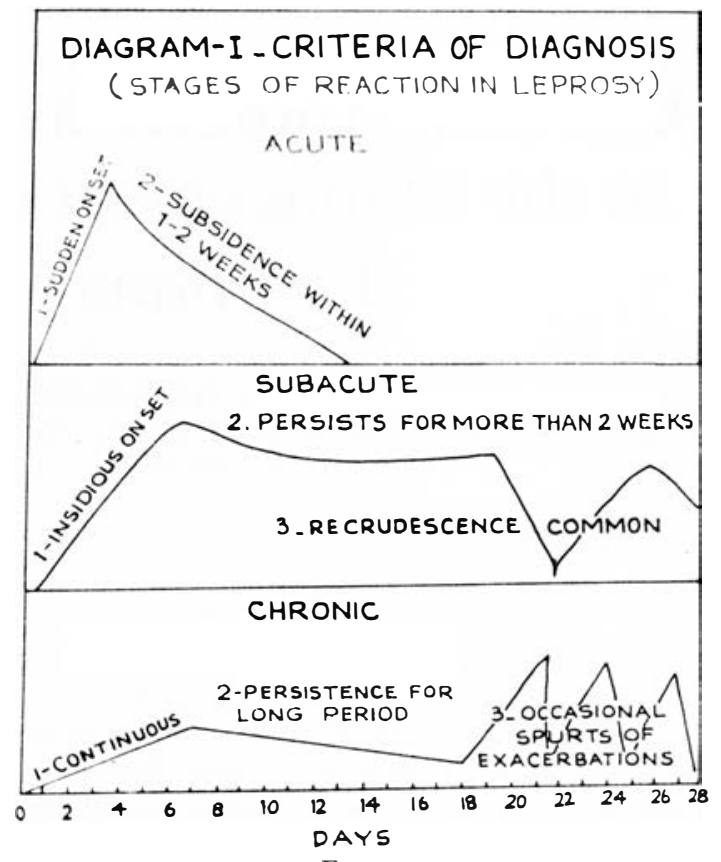

FIG. 2

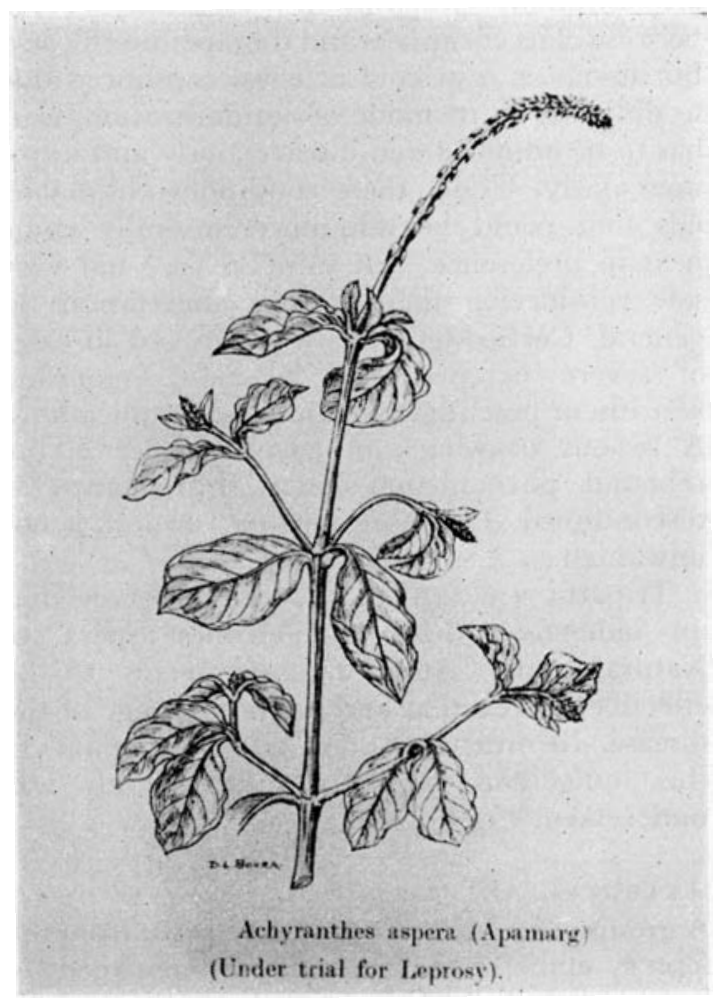

FIG. 4

I 6 Leprosy Review 
Records of their initial condition and their successive progress were maintained. Smears were taken and studied at least twice before the beginning of the treatment to minimize errors. History and clinical conditions of the cases were recorded by filling up history sheets prepared especially for the purpose; Clinical pictures of the cases were charted with the help of notations given in 'Notes on Leprosy' by Dr Dharmendra (1). Weight records were maintained. Bacteriological Index (B.I.) was calculated in each case by taking smears from 6 sites and adding the degrees of positivity of all the smears and dividing the total by the number of smears examined for future assessment ( $\left.{ }^{\mathbf{1}}\right)$. Complete Haematological examinations were done. Urinalysis and stool examinations were also carried out.

The results were assessed clinically and bacteriologically after 30 days of the treatment.

OISERVATIONS AND RESULTS

Out of 12 cases under investigation, 6 were of acute and subacute type of lepra-reaction, 3 of acute and subacute type of borderline reaction and 3 of subacute type of tuberculoid reaction. All these cases were in varying grades of severity, mild, moderate and severe (Fig. 5). Age and

\section{TABLE SHOWING CLINICAL OBSERVATION (STAGES AND GRADES OF SEVERITY OF REACTION (ASES)}

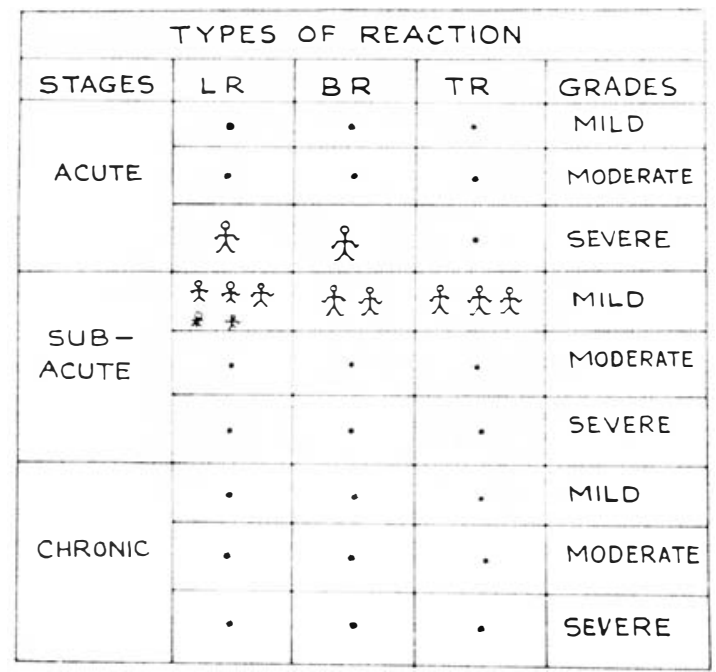

FIG. 5

\section{DIAGRAM SHOWING AETIOLOGICAL OBSERVATIONS \\ (AGE \& SEX INCIDENCE IN REACTION CASES)}

$\square$ MALE

UIIS FEMALE

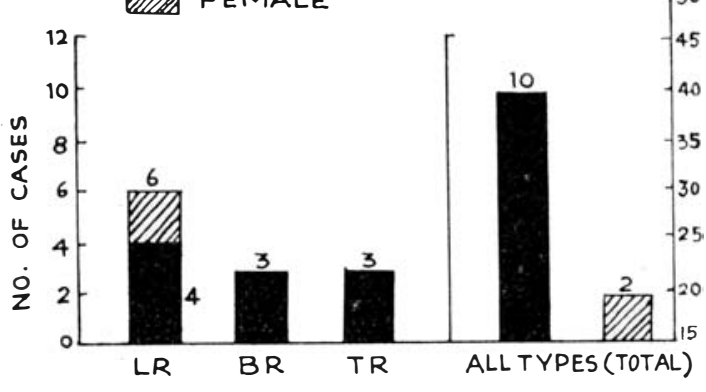

FIG. 6

sex incidence in reaction cases is given in Fig. 6.

Most of the cases showed a clear fall in the bacteriological index as well as clinical improvement. The most striking clinical improvement noted with this treatment was complete subsidence of Oedema which was invariably found in all the cases under investigation. It seems that the present drug under investigation has some anti-inflammatory as well as diuretic property which is yet to be confirmed. The cases also gained in weight and increase in Haemoglobin percentage (Figs. 7 and 8). This drug seems to have more useful effect in the therapy of reactions in leprosy of subacute and mild type. It can be administered saf ely to all cases irrespective of age and sex and is free of contraindications. In subacute and mild type of cases

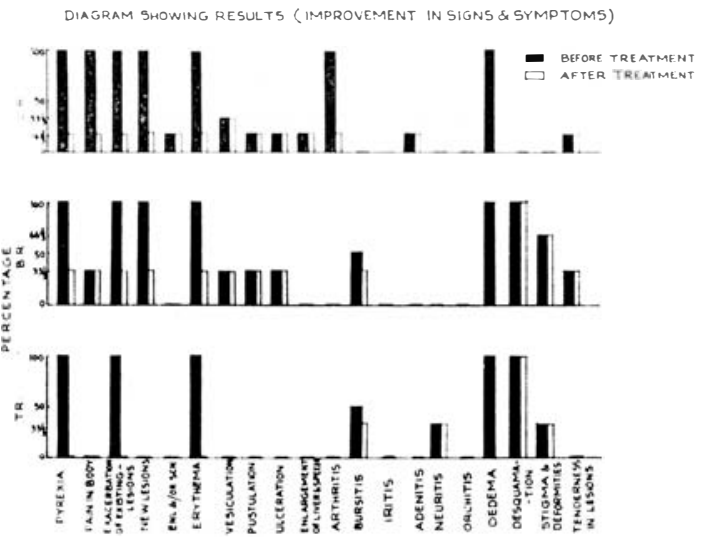

FIG. 7

Role of an Indigenous 


\section{DIAGRAM SHOWING RESULTS \\ (IMPROVEMENT IN WEIGHT HAEMOGLOBIN \\ \& BACTERIOLOGICAL INDEX)}
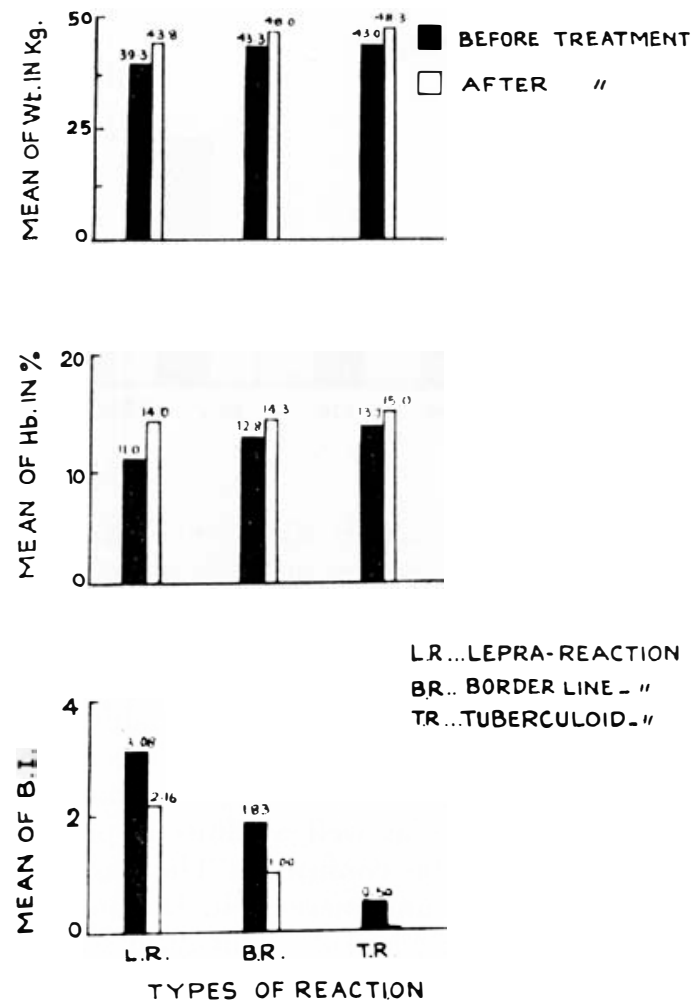

FIG. 8

withdrawal of anti-leprosy treatment is not necessary, but only reduction in dose, will suffice. For acute and severe reactions, of any type, it is necessary to administer other anti-reaction treatment along with this drug, because of slow response to treatment. Clinical pictures of the cases before and after treatment have been shown in Figs. 9 to 14.

In the acute and severe typc of reaction, the lesions took twice as much time to subside as fever. In the subacute type also a similar feature was noticed. However the administration of anti-reaction drugs in the treatment of reactions in leprosy is not only sufficient but it is also essential to recognise and note its readily changing form or appearance. Because if they are not recognised and cared for it might lead to a catastrophic end. To elude reaction in leprosy cases, carefully designed and judicious therapy with sulphones is highly essential. It should be induced in a slowly and gradually increasing dose and the same be maintained for a longer period. For management of conditions like acute severe neuritis and palsies, splinting of affected nerve and part with appropriate physiotherapeutic exercises is most essential to ensure rest and prevent stretching of the nerve and paralysed muscles.

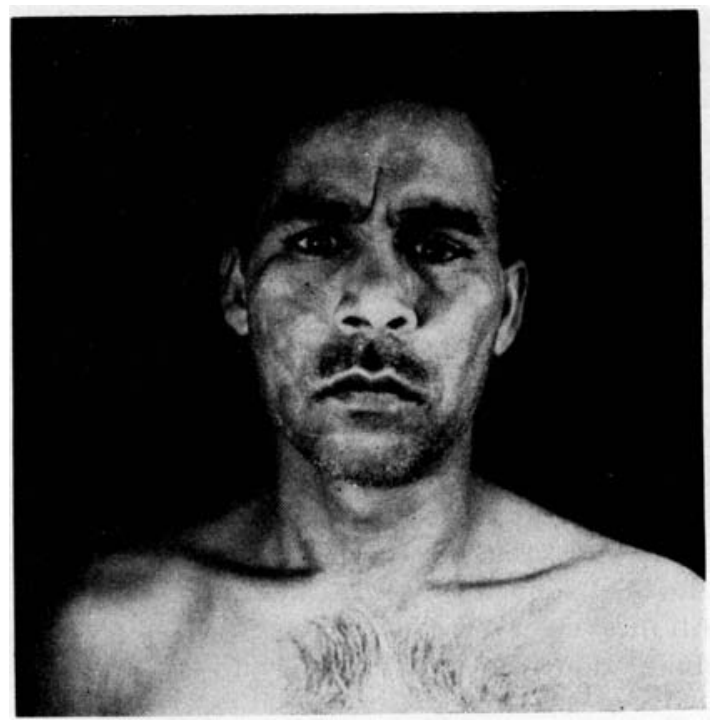

FIG. 9

Before treatment

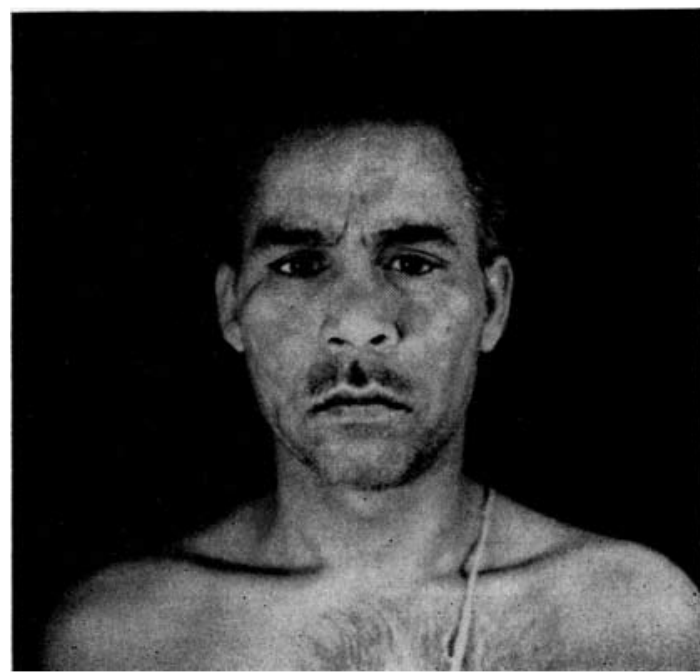

FIG. IO

30 days after treatment

\section{8 Leprosy Review}




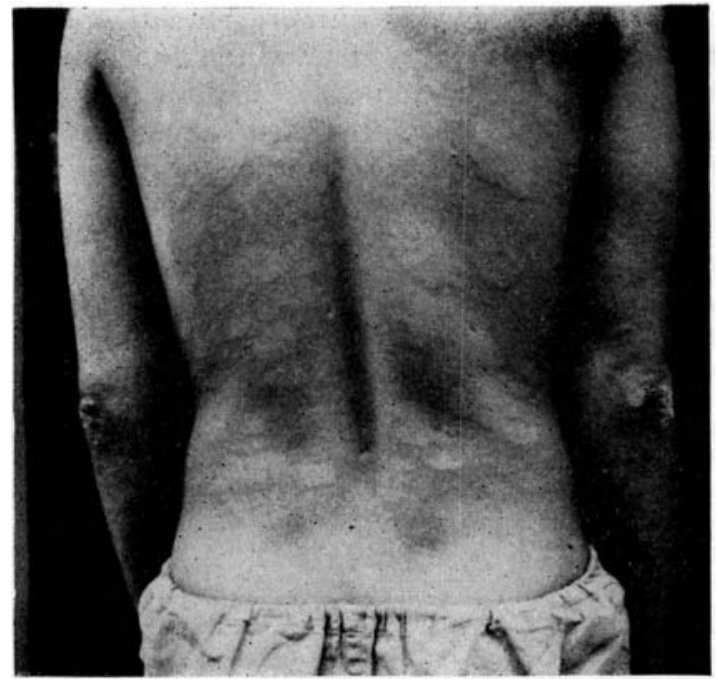

FIG. I I

$A$ case of Lepro-reaction before treatment

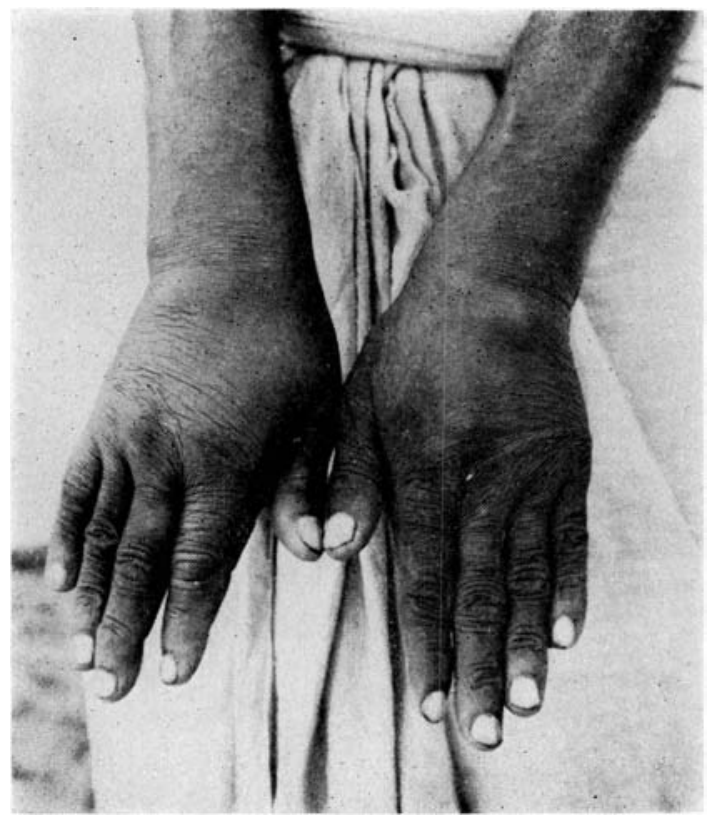

Fig. I 3

A case of Border-line reaction before treatment

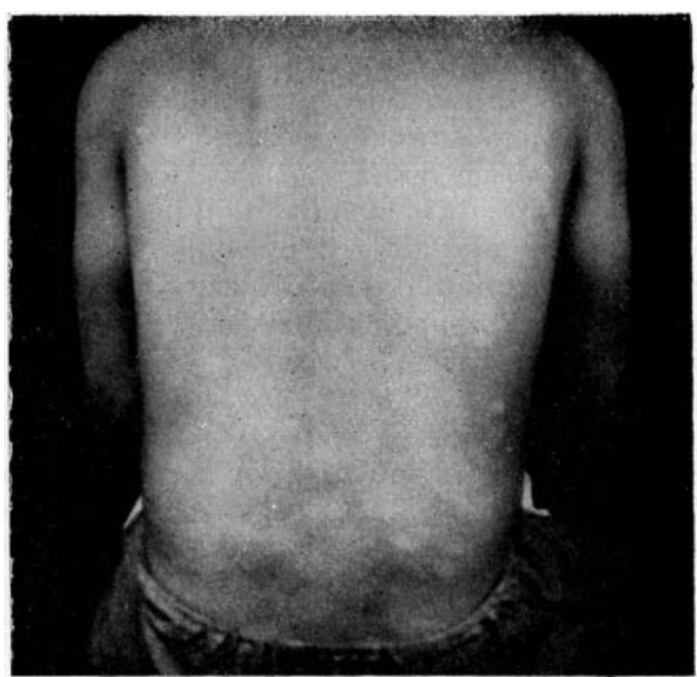

FIG. 12

30 days after treatment

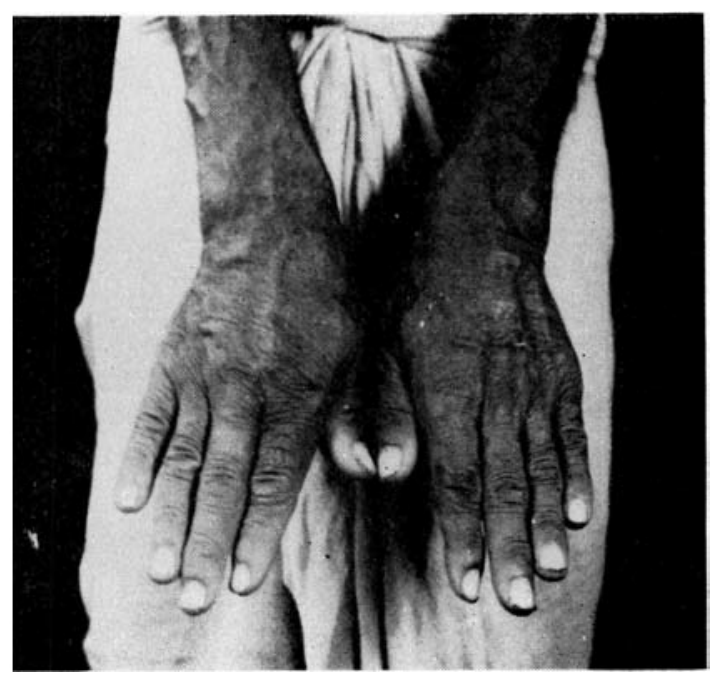

Fig. I 4

30 days after treatment

Role of an Indigenous Drug 
SUMMAR Y

(I) It is observed that 'Achyaranthes aspera' is effective in the therapy of reactions in leprosy particularly in subacute and mild type.

(2) It has been noted that this drug has not produced any toxic manifestation in any case.

(3) If it is administered in conjunction with sulphone (specific anti-leprosy drug) the chances of reaction become limited and the rate of improvement becomes faster.

\section{A CKNOWLEDGEMENTS}

We gratefully acknowledge Dr K. N. Udupa, Superintendent, S. S. Hospital, B.H.U., for permission to utilise the hospital records as well as for his day to day encouragements and to Dr Y. N. Upadhyaya, Head of the department, for providing the necessary facilities and suggestions. We are also thankful to the patients for their willing co-operation throughout the trial.

\section{REFERENCES}

I. Dharmendra, 'Notes on Leprosy', Published by the Ministry of Health, Government of India; New Delhi, I 960 .

2. RAMANUJAM, к., et al; 'Treatment of Lepra Reaction and some of its Special Manifestations', Leprosy in India, Vol. XXXVI, No. I Jan. I 964.

3. TRIPATHi, s. N., et al; 'Effect of Achyranthes aspera in the treatment of Leprosy' Journal of Medical Science, B.H.U., Vol. IV. No. 2, July i 963 . 